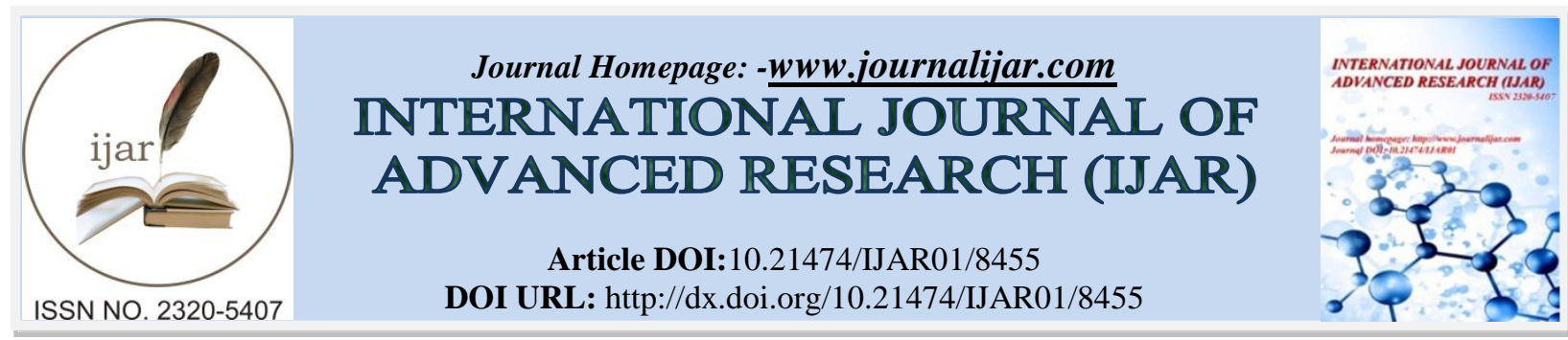

RESEARCH ARTICLE

\title{
LITISLAND: A TOOL FOR CASCADING KNOWLEDGE AND ENHANCE CRITICAL THINKING SKILL ON ENGLISH LITERATURE COMPONENTS.
}

Che Surhaizai binti Che Wil ${ }^{1,3}$, Muhammad Rizal bin Sadiman' ${ }^{1}$ and Melor Md Yunus ${ }^{3}$. Sekolah Menengah Kebangsaan Alor Pongsu \& Universiti Kebangsaan Malaysia.

\section{Manuscript Info}

\section{Manuscript History}

Received: 02 December 2018

Final Accepted: 04 January 2019

Published: February 2019

Key words:-

21st Learning Century, board game, collaborative learning, students centered.

\begin{abstract}
English literature has been officially implemented in Malaysia secondary school syllabus since year 2000. Most of the pupils response that learning literature components in four poems and a novel are to be less interesting. Thus, Lit was innovated to increase the pupils' interest and understanding in english literature and to trigger their creative and critical thinking skills. A research was conducted on 60 upper secondary pupils from bagan serai, malaysia to test the effectiveness of LITiSLAND. The questions featured in the LITiSLAND board games were invented to match with the literature components and lower order thinking skills (lots), higher order thinking skills (hots), bloom taxonomy and ryan thinker's keys in the construction process. An action research was used to test the effectiveness of this board game within three months to coincide with the $21^{\text {st }}$ - century learning. The instrument used for this research is questionnaires. The analysis of the instrument shows that $88 \%$ of pupils are strongly agree, $9.3 \%$ pupils agree and $2.66 \%$ went neutral that LITiSLAND is effective in helping them increasing their interest to learn and understand literature components. The post-test data proves that it helps to increase about $80 \%$ of pupils' marks. LITiSLAND has a major potential to help increasing pupils' interest and understanding towards learning English literature components where they can enjoy and have fun in learning, and at the same time master the topic.
\end{abstract}

Copy Right, IJAR, 2019,. All rights reserved.

\section{Introduction:-}

English Literature is one of the subject that has been brought in the learning syllabus around the world. English Literature has been introduced in Malaysian school syllabus since 2000 and has been implemented as an additional part of English subject in National Education Blueprint 2013-2025. It was introduced by our former Prime Minister, Datuk Seri NajibTunRazak in 2012. It is meant to establish Malaysia's ability to compete with other developed nation in global as English literature is collocated as a device to help increase English proficiency. MOE (2013) stated that language for aesthetic purposes enables learners to enjoy literary texts at a level suited to their language proficiency and develops in them the ability to express themselves creatively. The Education Blueprint 2013 aims to raise the Malaysian education standard to international level and prepare Malaysian children for the needs of the $21^{\text {st }}$ Century (Yunus\&Mohamad, 2016). However, most of the general perception towards literature is mundane; therefore, pupils are having low interest in learning it. Literature has been known as a boring and tough subject to 
understand. The state of Literature as a subject highlighted, among other things, its low status and lack of desirability (Poon, 2007). This subject requires a lot of reading and critical thinking skills to develop understanding for every components in learning it.

The implementation of Literature elements in English's syllabus have become one of the most challenging part for the teaching and learning session. These were obvious especially in rural schools, where pupils did not show interest in learning English not to mention literature itself. Many pupils did not consider the subject to be relevant to the contemporary elements. Regarding this, Dass (2013) highlighted that the vision and mision of the school and its performance have an impact on the degree of importance pupils placed on the subject. Pupils in the high performing schools were receptive to literature studies, commonly refers to schools in urban area. This is in contrary with the low performing schools in rural areas. This means that schools play the most important role in penetrating interests for pupils' acceptance for literature. MacBeath (1999) highlighted that it is an index of a nation's educational health when the school communities have a high level of intelligence and know how to use the tools of self-evaluation and self-improvement. This shows that the school itself is the most compatible model to influence their pupils whether to accept or to reject the implementation of literature in their learning. The way learning with literature is shaped within different educational systems is influenced by current concepts of education ("Bildung"), of culture, aesthetics and literature, of language and learning (Stan, 2014).

LITiSLAND was designed as a medium of cascading knowledge and also to increase pupils' knowledge and understanding in learning literature and at the same time to enhance their creative and critical thinking skills. It is a board game that specifically play a role as a teaching aid to improve pupils' interest in English Literature. LITiSLAND is a combination of two words; 'Literature' and 'Island' to make it sounds more interesting and easy to remember. LITiSLAND changes the perception where it implements the knowledge of literature components in the shape of a game. Players must answer the questions from the deck but before buying the properties, they have to answer the questions correctly. The winner will be declared by three means; their asset values or the amount of gold they have collected at the end of the game or the first one to reach the LITiSLAND with a Dragon. It provides positive impacts to improve collaborative learning and freedom in exploring the knowledge. Pupils' interest on learning literature should be triggered by activities that can enhance their needs to learn. Pupils' should realize the effectiveness and the relevance of learning literature in their daily syllabus.

The aim of this paper is to identify whether LITiSLAND can help to overcome the difficulties pupils face in developing ideas in learning literature components. It is also to measure to what extend LITiSLAND has helped to enhance critical thinking skills in learning literature to coincide with 21 st-century learning. Pupils should enjoy learning literature with the implementation of a board game to develop their knowledge and creativity.

\section{Review of Related Literature}

The research is based on several researchers. One of the researchers is the Toolkits for $21^{\text {st }}$ Century Teaching : Practical Implications for the $4^{\text {th }}$ Industry Skills Development by Abdul Majid et al. (2017) highlighted that the practices in critical thinking would assist learners to be accurate and specific in discussing or noting what is relevant or irrelevant regarding the subject learnt. The implementation of $21^{\text {st }}$ century learning leads to the innovation of numerous activities to develop creative and critical thinking skills. Therefore, to remain relevant and to be able to compete in the $21^{\text {st }}$ century industry, a need for critical thinking skills becomes a pivotal. This is due to the demands of living in the digital world where pupils entering the workforce, must solve complex multidisciplinary problems, work successfully in teams, exhibit effective oral and written communication skills, and practice good interpersonal skills. In term of ESL education, it enhances language and presentation skills. Therefore, the innovation of LITiSLAND was to respond to the implementation of $21^{\text {st }}$ - Century learning, where it requires skills that is generally used to refer to certain core competencies

In the Personalizing Learning of English Literature : Perception and Challenge by Othman et al. (2015) research revealed that pupils are interested in learning literature with the integration of ICT. Therefore, it also highlighted that teachers should incorporate current technologies in their literature lesson to cater pupils' needs. Teachers should be made to rediscover the joy of learning literature so that they do not become too dependent on worksheets and workbooks available in the market. The research highlighted that literature lesson as an interesting lesson if the teachers plan and carry out creative activities such as role playing, story telling and games. These pupils prefer a more structured program through interactive learning by themselves. By creating some activities during the teaching and learning session, it will develop their interest in learning literature. The pupils were engaged in oral 
interaction with the whole class even though there was no collaboration work and not all learners had the opportunity to use ICT (Zainal, 2012). Initial observation shows that the English literature instructors do use ICT application in their English literature classes (Muhammad, Abdullah \&Hamzah, 2016). Muhammad, Abdullah \&Hamzah (2016) also highlighted that when the lessons are interactive and practical, students tend to be more cooperative and focus especially to value a literary text.

Secondary schools' pupils are better known as teenagers, and they are all love playing games and having interactive learning activities along. One of the instructional games is board game. Creative Adapting e-Learning Board Games for School Settings Using the ELG Environment by Retalis (2008) highlighted that adding board games to the educational process can lead to an interactive stimulating learning experience. Board games players often learn from one another while having fun in a competitive environment. Meanwhile, in the research entitle Instructional Gaming Implication for Instructional Technology by John (1994), highlighted that instructional games are more effective if they are embedded in instructional programs that include debriefing and feedback. Games should be used as adjuncts and aids, not a stand-alone instruction so that the instructional support during plays increases the effectiveness of it. Games are useful in teaching and learning practices and have to serve many functions such as tutoring, amusing, helping to explore new skills, promoting self esteem, practicing skills or seeking to charge attitudes. Although this can be very challenging and time consuming, interactive, collaborative and competitive games tend to motivate and encourage student participation in the learning process (Milczynski, 2011). Thus, the invention of LITiSLAND is to fulfill the needs of providing fun learning for pupils. They will gain more information and knowledge if they play continuously in the time frame given.

\section{Methodolgy:-}

The study have used both quantitative and qualitative research methods and focuses to employ action research as the basis of the research to help the pupils to utilize LITiSLAND as a tool to scaffold pupils' understanding towards English literature components. Besides that, the research design for this study based from Kemmis and McTaggart model of action research (Kemmis, McTaggart, \&Retallick, 2004). The study was conducted in a rural school in BaganSerai, Malaysia. The participants for this research are limited to 60 upper secondary pupils from intermediate level of proficiency. There is a comparison between Test 1 (March) and Test 2 (June) where LITiSLAND were first implemented.

\section{Research Instruments}

The research instrument that was used is a set of questionnaire, which consists of 10 questions. This is because, according to Fraenkel, Wallen\& Hyun (as cited by Lee et. al, 2013), the questionnaires can help researchers to see the effectiveness of a research meticulously. The questionnaires were then collected and analyzed. Five Likert scales were used to justify the respondents' level of approval towards each set of a statement (Wyse, 2012). The use of Likert scale is valuable and important in action research. The questionnaires were then collected and analyzed.

\section{Procedures}

The process of gathering information was initiated by interviewing the English Language teachers and upper form pupils regarding the problems they were facing when it comes to teaching and learning English Literature components. Then, the idea of the board game, colors selection as well as the types of questions to be featured was drafted. The set of questions for the board game, which consists of LOTS and HOTS, were generated based on Bloom Taxonomy and Ryan Thinker's Keys. The board, cards, and currencies were designed by using Adobe Photoshop CS6. Next, the final designs were printed. Two weeks before Test 2, pupils were asked to play LITiSLAND as a form of revision. After that, they had to answer the questionnaires. Finally, the pupils sat for Test 2 .

\section{Finding And Discussion:-}

The data from the questionnaires were processed by using qualitative and quantitative research methods to determine the effectiveness of using LITiSLAND as a tool to increase pupils' interest and understanding towards English Literature components. The pupils' marks between Test 1 and Test 2 for English Literature were collected and compared then the positive increments in term of the marks obtained by the pupils could be seen. The data were tabulated as shown in Table 2. 
Table 1:-Results of Questionnaire Analysis

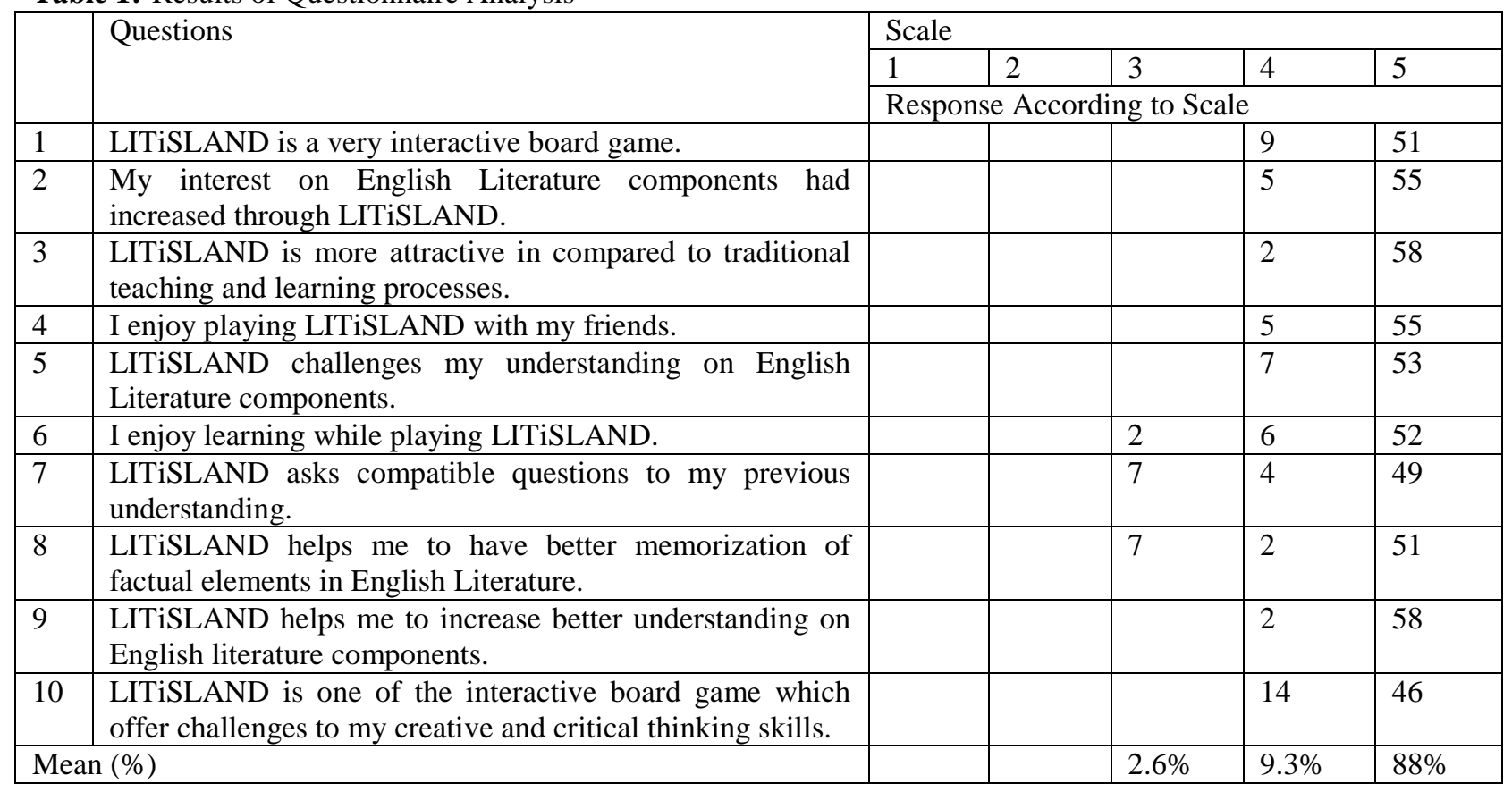

Table 1 shows the results of the questionnaire analysis on 60 pupils in which $88 \%$ of the respondents strongly agreed, $9.3 \%$ agreed and $2.6 \%$ went neutral that LITiSLAND is effective in helping them to increase their interest to learn and understand English literature components. The results were calculated by using the mean score. To indicate the improvement in the pupils' achievement, below is the comparison of the marks obtained from the two tests. A huge improvement can be seen where $81.6 \%$ of pupils achieved the score of $70 \%-79 \%$ compared to $13.3 \%$ previously.

Table 2:-Score Comparison of Test 1 (March) and Test 2 (June)

\begin{tabular}{|l|l|l|l|l|l|}
\hline Test 1 Score (\%) & Amount & $\begin{array}{l}\text { Percentage } \\
(\%)\end{array}$ & Test 2 Score (\%) & Amount & Percentage (\%) \\
\hline $40-49$ & 15 & 25 & $40-49$ & - & - \\
\hline $50-59$ & 12 & 2 & $50-59$ & 3 & 5 \\
\hline $60-69$ & 22 & 41.6 & $60-69$ & 3 & 5 \\
\hline $70-79$ & 8 & 13.3 & $70-79$ & 49 & 81.6 \\
\hline $80-89$ & 3 & 5 & $80-89$ & 5 & 8.3 \\
\hline $90-100$ & - & - & - & - & - \\
\hline
\end{tabular}

Based on the findings, it could be concluded that LITiSLAND helps overcome the difficulties pupils face in developing ideas in learning literature components. This innovation helps to increase pupils' interest and understanding in learning literature. This is because LITiSLAND is not only interesting and unique in design but it is also loaded with important information, which helps pupils to explore the English literature components while having fun.

LITiSLAND also helps in promoting collaborative learning and enhancing pupils' creative and critical thinking skills in learning literature to coincide with 21 st-century learning. It exposed a fun learning session where pupils involved in the hands-on activities by playing board games and at the same time they know how to overcome problems occurred in learning literature. It also helps them think critically by indulging themselves in activities.

\section{Conclusion And Implication:-}

As a conclusion from the study, it could be concluded that the LITiSLAND was able to help to overcome the difficulties pupils face in developing ideas in learning English literature components. It is found that it could bring positive effect to promote enjoyment and facilitates the learning process. This was proven by the pupils' increasing 
scores, their positive feedback during the interview and the responses from the analysis of questionnaire. Thus, it is also concluded that LITiSLAND does help to enhance critical thinking skills in learning English literature to coincide with 21 st-century teaching and learning process. The use of LITiSLAND is to complement pupils' revision materials and it is suitable to develop pupils' interest in learning. Pupils love to involve in fun and interactive activities and at the same time develop their knowledge. It also helps to ease teacher to teach literature components in class, which will solve the problem of boredom and eventually changes pupils' prior perception towards English Literature components. Kaur\&Mahmor (2014) highlighted that Literature should no longer be considered merely as a tool to increase English proficiency, it should serve as a bridge to educate young Malaysian about their rich, literary traditions, heritage and culture.

\section{References:-}

1. Dass, R. (2013). Literature and the $21^{\text {st }}$ Century Learner. Procedia: Social and BehaviouralScience. Vol. 123: 289-298.

2. Abdul Majid, F. MdZamin, A, A. \&Kamarudin, M, F. (2017). Toolkits for $21^{\text {st }}$ Century Teaching : Practical Implications for the $4^{\text {th }}$ Industry Skills Development. Shah Alam. UniversitiInstitutTeknologi Mara.

3. Fraenkel, Wallen\& Hyun (2012). How to design and evaluate research in education. New York: McGraw-Hill.

4. John, D. (1994). Instructional Gaming Implication for Instructional Technology. Annual Meeting of the Association. 131-150

5. Kaur, P. \&Mahmor. (2014). Examining the role of the Englishliterature component in the Malaysian English curriculum. Procedia - Social and Behavioural Sciences 134 (2014) 119 - 124.

6. KementerianPendidikan Malaysia. (2014) Kurikulum Standard SekolahMenengah. Putrajaya, Malaysia.

7. Kemmis, S., McTaggart, R., \&Retallick, J. (Eds.). (2004). The action research planner (2nd ed. rev.). Karachi:

8. Aga Khan University, Institute for Educational Development.

9. MacBeath, J. (1999). Schools Must Speak For Themselves : The case for school self-evaluation. Published in USA and Canada :Routledge.

10. Milczynski, K. A. (2011). Literature Review: Effectiveness of Gaming in the Classroom. Michigan State University.

11. Ministry of Education (2013). Malaysia National Education Blueprint 2013 - 2015, Putrajaya, Malaysia.

12. Ministry of Education (201). Curriculum Specifications for Form 4, Putrajaya, Malaysia.

13. Muhamad, S. H. Abdullah, E. \&Hamzah, M. (2016). The Application of ICT in English Literature Classrooms. GLIT E-Journal on Information Technology and Language Practice. Vol 2.

14. Othman, N, I. Shah, P, M. Karim, A. A. Yusof, A. Din, R. Ramli, N, A. \& Mat Salleh,N, S.(2015). Personalizing Learning of English Literature : Perception and Challenge. Journal of Personalized Learning. 1(1): 104-112.

15. Poon, A. (2007). The Politics of Pragmatism: Some Issues in the Teaching of Literature in Singapore. Changing English: Studies in Culture and Education, 14 (1), 51-59. London: Routledge.

16. Retalis, S. (2008). Creative Adapting e-Learning Board Games for School Settings Using the ELG Environment. Journal of Computer Science. Vol.14, no. 17 : 2897-2908.

17. STAN, R, V. (2015). The importance of literature in primary school pupils' development and personalgrowth. Procedia - Social and Behavioral Sciences 180 (2015) 454 - 459.

18. Wyse,S.(2012). Why use Likert Scale in survey?Retrieved from http://www.snapsurveys.com/blog/demographics-questions-surveys/

19. Yunus, M. M,.Mohamad, M. \& Lim, P.W.S. (2016). The Malaysian Education Blueprint 2013 and Its Effects on English Language Teaching in Malaysia. Asian EFL Journal.

20. Zainal, A. (2012). ESL teachers' use of ICT in teaching English Literature: An analysis of teachers' TPCK. Procedia - Social and Behavioral Sciences 34 (2012) 234 - 237. 